\title{
Role of insulin-like growth factor binding protein-3 in glucose and lipid metabolism
}

\author{
Ho-Seong Kim, MD, PhD \\ Department of Pediatrics, \\ Severance Children's Hospital, \\ Yonsei University College of \\ Medicine, Seoul, Korea
}

\begin{abstract}
Insulin-like growth factor binding protein (IGFBP)-3 has roles in modulating the effect of IGFs by binding to IGFs and inhibiting cell proliferation in an IGF-independent manner. Although recent studies have been reported that IGFBP-3 has also roles in metabolic regulation, their exact roles in adipose tissue are poorly understood. In this review, we summarized the studies about the biological roles in glucose and lipid metabolism. IGFBP-3 overexpression in transgenic mice suggested that IGFBP-3 results in glucose intolerance, and insulin resistance. IGFBP-3 knockout (KO) mice exhibited normal insulin level and glucose response after glucose challenge. More recent study in IGFBP-3 KO mice with a high-fat diet demonstrated that IGFBP-3 KO mice exhibited elevated fasting glucose and insulin, but normal response to glucose challenge, suggesting that IGFBP-3 $\mathrm{KO}$ mice may induce insulin resistance even though preserved insulin sensitivity. In vitro and in vivo studies using 3T3-L1 adipocytes and rat, IGFBP-3 induced insulin resistance by inhibiting glucose uptake. In contrast, the reduced levels of IGFBP-3 in obesity might induce insulin resistance by suppression of IGFBP-3's anti-inflammatory function, suggesting IGFBP-3 has a protective effect on insulin resistance. Also, proteolysis of IGFBP-3 might contribute to the insulin resistance in obesity and type 2 diabetes mellitus. In addition, IGFBP-3 inhibited adipocyte differentiation, suggesting IGFBP-3 may contribute to the insulin insensitivity. Taken together, it is not yet certain that IGFBP-3 has a protective effect or enhancing effect on insulin resistance, and more studies will be needed to clarify the roles of IGFBP-3 in metabolic regulation.
\end{abstract}

Keywords: Insulin-like growth factor binding protein-3, Insulin resistance, Adipocytes, Metabolism

\section{Introduction}

Insulin-like growth factor binding protein (IGFBP)-3 is the most abundant IGFBP in serum, and comprises 150-kDa ternary complex with insulin-like growth factor (IGF)-I and an acid labile subunit (ALS), thereby prolonging the half-life of IGF-I in circulation. The major function of IGFBP-3 has been proposed to involve IGF binding and modulate the diverse biological actions of the IGFs, such as cell proliferation, differentiation, an increase in metabolic activity, and cell survival by regulating their access to the IGF-I receptor ${ }^{1-3}$. Additionally, IGFBP-3 exhibits clear and distinct biological effects, including inhibition of cell proliferation and inducing apoptosis in various cell types in an IGF-independent manner ${ }^{4-8)}$. Mechanisms for this IGF-independent actions of IGFBP-3 have been demonstrated that IGFBP-3 increases the ratio of proapoptotic to antiapoptotic proteins ${ }^{9)}$, or activates the caspases involved in a death receptor-mediated pathway ${ }^{10)}$ to induce apoptosis, and arrests cell cycle in G1/S phase to inhibit cell growth ${ }^{11)}$.

Recently, issue about the possible role of IGFBP-3 in metabolic regulation has been raised. Apart from conventional concept indicating that IGFBP-3 was used to involve in meta-bolic regulation by modulating IGF bioavailability, several studies have been reported that IGFBP-3

Tel: +82-2-2228-2069

Fax: +82-2-393-9118

E-mail:kimho@yuhs.ac 
may have metabolic role independent of the IGF axis. However, most part of the exact role of IGFBP-3 in glucose and lipid metabolism remains poorly understood. In this review, focus will be placed on the actions of IGFBP-3 in glucose and lipid metabolism.

\section{IGFBP-3-overexpressing transgenic mice study}

IGFBP-3 overexpression in transgenic (Tg) mice in early studies exhibited little effect on birth weight, litter size and body weight other than some selective effect on organ growth, such as spleen, liver and heart ${ }^{12,13)}$. However, these studies were accomplished in conditions showing only modest increase of IGFBP-3 expression. Use of the mouse phosphoglycerate kinase I and the cytomegalovirus promoters to overexpress IGFBP-3 more effectively demonstrated 4.9- to 7.7-fold increase in serum level of IGFBP-3, and resulted in modest intrauterine and postnatal growth retardation, probably because of reduced IGF-I bioavailability, and showed heavier liver and epididymal fat masses compared with wild-type (WT) mice ${ }^{14)}$. This Tg mice also showed dramatic metabolic changes: increased levels of fasting glucose and insulin, increased response to a glucose challenge, attenuated hypoglycemic effects of insulin and IGF-I, and reduced uptake of 2-deoxyglucose in muscle and adipose tissue $^{15)}$. These data suggest that overexpression of IGFBP-3 results in fasting hyperglycemia, glucose intolerance, and insulin resistance. However, we have to be cautious to interpret these data on the basis of the finding that environment by overexpression of IGFBP-3 in Tg mice may not be expected in real body.

\section{IGFBP-3-knockout (KO) mice study}

It has been reported that body weight of IGFBP-3 KO mice was indistinguishable from WT, demonstrating that pre-natal and post-natal growth was not affected by IGFBP-3 $\mathrm{KO}^{16)}$. The response to a glucose challenge in IGFBP-3 $\mathrm{KO}$ mice was same as that in WT. However, IGFBP-3-4-5 triple KO mice showed lower glucose and higher insulin levels after glucose challenge compared with WT mice, indicating that IGFBP-3-4-5 triple KO mice have increased glucose uptake and enhanced glucose clearance. Another study performed phenotypic comparisons of controls and four mouse lines with genetic mutants: liverspecific IGF-I deficiency (LID), ALS KO (ALSKO), IGFBP-3 KO (BP3), and a triply deficient LID/ALSKO/BP3 line (LAB) ${ }^{17}$. This study demonstrated that LID and LAB mice showed increased levels of serum insulin, probably due to increases in growth hormone $(\mathrm{GH})$ and secondary insulin resistance. ALSKO mice exhibited increased glucose clearance on glucose tolerance test, reflecting increase of $\beta$-cell function and insulin sensitivity, while LID and LAB mice showed reduced clearance. In contrast, IGFBP-3 KO mice exhibited normal insulin level and glucose response after glucose challenge. More recent study in IGFBP-3 KO mice with a high-fat diet demonstrated that IGFBP-3 KO mice exhibited heavier weight, decreased resting metabolic rate, and elevated fasting glucose and insulin levels ${ }^{18)}$. However, IGFBP-3 KO mice had relatively normal glucose response after glucose challenge, and increased basal hepatic glucose production, but after insulin stimulation during hyperinsulinemic clamps, indicating that IGFBP-3 KO mice preserve insulin sensitivity despite evidence of increased basal glucose turnover.

Data from several studies did not show solid and consistent findings about the effect of IGFBP-3 KO on glucose metabolism. This discrepancy may come from many compounding and complicated factors in these studies. For example, IGF system is comprised of IGFs, type I and II IGF receptors, IGFBPs, and IGFBP proteases, and is working in a very complicated ways affecting influences on each other. Moreover, the prevalence of IGF-I complexes composing with IGF-I, ALS, and IGFBPs in serum and/or in tissues produces different effects on GH secretion and carbohydrate metabolism. Also, there is a possibility that changes in expression and bioactivity of IGFBP-3 in extrahepatic tissues can affect carbohydrate metabolism ${ }^{17)}$. Moreover, each experiment was done in different conditions, such as diet (fasting, fed with normal chow, or fed high-fat diet), and age at the time of experiment. Nevertheless, it is of note that IGFBP-3 KO mice with a high-fat diet had heavier weight compared with WT and showed fasting hyperglycemia and hyperinsulinemia, indicating insulin resistance, even not in glucose tolerance test ${ }^{18)}$.

\section{In vitro and in vivo study}

It has been reported that IGFBP-3 may lead to insulin resistance in adipocytes ${ }^{19)}$. In this report, IGFBP-3 reduced insulin-stimulated but not basal glucose uptake in 3T3$\mathrm{L} 1$ adipocytes independent of the IGF axis. IGFBP-3 also reduced insulin-stimulated glucose transporter- 4 translocation to the plasma membrane. This inhibitory effect of IGFBP-3 was accomplished through the decrease in threonine phosphorylation of Akt, but not insulin receptor phosphorylation. Another study also reported that IGFBP-3 induces insulin resistance in adipocytes in vitro and in rats in vivo ${ }^{20)}$. Kim et al. ${ }^{20)}$ reported that IGFBP-3 inhibits basal and insulin-stimulated glucose uptake in 3T3-L1 adipocytes through the decrease in insulin receptor phosphorylation, and proposed that a possible role for IGFBP-3 in cytokine-induced insulin resistance. They also demonstrated that infusion of IGFBP-3 to rats for 3 hours or 7 days inhibits peripheral glucose uptake and glycogen synthesis suggesting in vivo effect of IGFBP-3.

In contrast, a recent study reported that IGFBP-3 inhibits cytokine-induced insulin resistance and early manifestations of atherosclerosis $^{21)}$. Mohanraj et al. ${ }^{21)}$ demonstrated that IGFBP-3 inhibits tumor necrosis factor (TNF)-a-induced nuclear factor $(\mathrm{NF})-\kappa \mathrm{B}$ activity in an IGF-independent manner, thereby restoring the deregulated insulin signaling and negating TNF- 
a-induced inhibition of glucose uptake. IGFBP-3 further inhibits TNF- $a, \mathrm{C}$-reactive protein and high glucose-induced NF- $\kappa B$ activity in human aortic endothelial cells (HAECs) and subsequently suppresses monocyte adhesion to HAEC through the IGFBP-3 receptor. This study suggested that IGFBP-3 may have a distinct function in pathologic or disease state. This study also exhibited that IGFBP-3 dose not affect insulin-induced glucose uptake even under normal conditions. Another study showing that diet-induced obese rats exhibited a downregulation of IGFBP-3 expression in mesenteric fat suggests that IGFBP-3 may have a protective effect against obesity ${ }^{22}$.

IGFBP-3 may have a regulatory function on lipid metabolism. Chan et al. ${ }^{23)}$ reported that IGFBP-3 interferes with the peroxisome proliferator-activated receptor (PPAR) $\gamma$-dependent process of adipocyte differentiation and maintenance of the gene expression characteristic of mature adipocytes. These changes were associated with a decrease in lipid accumulation ${ }^{23)}$ and adiponectin expression ${ }^{20)}$ in cells treated with IGFBP-3 during differentiation. Further, IGFBP-3 activates inhibitory Smad signaling in 3T3-L1 cells and that endogenous IGFBP-3 modulates their adipogenic differentiation by regulating cell sensitivity towards the inhibitory effect of transforming growth factor- $\beta^{24)}$. Since adipocyte differentiation is required to mediate insulin sensitivity in adipocytes ${ }^{25}$, this inhibitory effect of IGFBP- 3 on adipocyte differentiation may contribute to progression towards insulin resistance. In contrast, Grohmann et al. ${ }^{26)}$ reported that IGFBP-3 as well as IGF-I stimulates glycerol3-phosphate dehydrogenase activity during differentiation of preadipocytes isolated from adipose tissue of children, indicating that IGFBP-3 enhances adipocyte differentiation. It is not yet determined whether IGFBP-3 can be either inhibitory or stimulatory to the cell differentiation according to the cell types or culture conditions, and the mechanisms of such a divergence of the IGFBP-3's effect are poorly understood ${ }^{277}$.

\section{Study about IGFBP-3 proteolysis}

Proteolysis of IGFBP-3 may contribute to the insulin resistance of pregnancy, obesity, and type 2 diabetes mellitus. Yamanaka et al. ${ }^{28}$ demonstrated that $\mathrm{NH}_{2}$-terminal fragment of IGFBP-3 binds insulin with high affinity and blocks insulin action by inhibiting autophosphorylation of the insulin receptor $\beta$ subunit and phosphorylation of insulin receptor substrate- 1 . The conserved $\mathrm{NH}_{2}$-terminal and $\mathrm{COOH}$-terminal sequences of IGFBP-3 and the appropriated ternary structures formed by disulfide bonds result in high affinity for IGFs but low affinity for insulin. When IGFBP-3 is reduced or fragmented, the insulin binding site at the $\mathrm{NH}_{2}$-terminus of IGFBP- 3 is exposed, resulting in increased affinity for insulin and diminished affinity for IGFs ${ }^{28}$. Increased proteolysis of IGFBP-3 has been observed in serum from patients with type 2 diabetes mellitus ${ }^{29)}$, and simple obesity ${ }^{21,30)}$. Mohanraj et al. ${ }^{21)}$ reported that proteolyzed IGFBP-3 positively correlates with adiposity parameters such as waist circumference, body mass index, fasting insulin, and insulin resistance index such as homeostasis model assessment of insulin resistance in overweight and obesity population. These studies suggest that increased proteolytic fragments of IGFBP-3 in obese individuals probably induces insulin resistance by resulting in reduced serum levels of insulin thereby inhibiting insulin action, and reduced levels of intact IGFBP-3 thereby inhibiting its IGF-independent anti-inflammatory functions.

\section{Conclusions}

There is a line of evidence that IGFBP-3 plays an important role in glucose and lipid metabolism. However, previous studies about the roles of IGFBP-3 in metabolic regulation did not provide convincing evidence. It is not yet certain that IGFBP-3 has a protective effect or enhancing effect on inducing insulin resistance. Further, the mechanism of the effect of IGFBP-3 in regulating metabolism has to be elucidated. More clinical, epidemiological, and biochemical studies will be needed to clarify the roles of IGFBP-3 in glucose and lipid metabolism.

\section{Conflict of interest}

No potential conflict of interest relevant to this article was reported.

\section{References}

1. Jones JI, Clemmons DR. Insulin-like growth factors and their binding proteins: biological actions. Endocr Rev 1995;16:3-34.

2. Firth SM, Baxter RC. Cellular actions of the insulin-like growth factor binding proteins. Endocr Rev 2002;23:82454.

3. Blat C, Delbe J, Villaudy J, Chatelain G, Golde A, Harel L. Inhibitory diffusible factor 45 bifunctional activity. As a cell growth inhibitor and as an insulin-like growth factor I-binding protein. J Biol Chem 1989;264:12449-54.

4. Cohen P, Lamson G, Okajima T, Rosenfeld RG. Transfection of the human insulin-like growth factor binding protein-3 gene into Balb/c fibroblasts inhibits cellular growth. Mol Endocrinol 1993;7:380-6.

5. Oh Y, Muller HL, Lamson G, Rosenfeld RG. Insulinlike growth factor (IGF)-independent action of IGFbinding protein-3 in Hs578T human breast cancer cells. Cell surface binding and growth inhibition. J Biol Chem 1993;268:14964-71.

6. Valentinis B, Bhala A, DeAngelis T, Baserga R, Cohen P. The human insulin-like growth factor (IGF) binding protein-3 inhibits the growth of fibroblasts with a targeted disruption of the IGF-I receptor gene. Mol Endocrinol 1995;9:361-7.

7. Rajah R, Valentinis B, Cohen P. Insulin-like growth factor (IGF)-binding protein-3 induces apoptosis and 
mediates the effects of transforming growth factor-betal on programmed cell death through a p53- and IGFindependent mechanism. J Biol Chem 1997;272:12181-8.

8. Gill ZP, Perks CM, Newcomb PV, Holly JM. Insulin-like growth factor-binding protein (IGFBP-3) predisposes breast cancer cells to programmed cell death in a non-IGFdependent manner. J Biol Chem 1997;272:25602-7.

9. Butt AJ, Firth SM, King MA, Baxter RC. Insulin-like growth factor-binding protein-3 modulates expression of Bax and Bcl-2 and potentiates p53-independent radiation-induced apoptosis in human breast cancer cells. J Biol Chem 2000;275:39174-81.

10. Kim HS, Ingermann AR, Tsubaki J, Twigg SM, Walker GE, Oh Y. Insulin-like growth factor-binding protein 3 induces caspase-dependent apoptosis through a death receptormediated pathway in MCF-7 human breast cancer cells. Cancer Res 2004;64:2229-37.

11. Kim HS, Lee WJ, Lee SW, Chae HW, Kim DH, Oh Y. Insulin-like growth factor binding protein-3 induces G1 cell cycle arrest with inhibition of cyclin-dependent kinase 2 and 4 in MCF-7 human breast cancer cells. Horm Metab Res 2010;42:165-72.

12. Murphy LJ, Molnar P, Lu X, Huang H. Expression of human insulin-like growth factor-binding protein-3 in transgenic mice. J Mol Endocrinol 1995;15:293-303.

13. Murphy LJ, Rajkumar K, Molnar P. Phenotypic manifestations of insulin-like growth factor binding protein-1 (IGFBP-1) and IGFBP-3 overexpression in transgenic mice. Prog Growth Factor Res 1995;6:425-32.

14. Modric T, Silha JV, Shi Z, Gui Y, Suwanichkul A, Durham SK, et al. Phenotypic manifestations of insulin-like growth factor-binding protein-3 overexpression in transgenic mice. Endocrinology 2001;142:1958-67.

15. Silha JV, Gui Y, Murphy LJ. Impaired glucose homeostasis in insulin-like growth factor-binding protein-3-transgenic mice. Am J Physiol Endocrinol Metab 2002;283:E937-45.

16. Ning Y, Schuller AG, Bradshaw S, Rotwein P, Ludwig T, Frystyk J, et al. Diminished growth and enhanced glucose metabolism in triple knockout mice containing mutations of insulin-like growth factor binding protein-3, -4, and -5. Mol Endocrinol 2006;20:2173-86.

17. Yakar S, Rosen CJ, Bouxsein ML, Sun H, Mejia W, Kawashima Y, et al. Serum complexes of insulin-like growth factor-1 modulate skeletal integrity and carbohydrate metabolism. FASEB J 2009;23:709-19.

18. Yamada PM, Mehta HH, Hwang D, Roos KP, Hevener AL, Lee KW. Evidence of a role for insulin-like growth factor binding protein (IGFBP)-3 in metabolic regulation. Endocrinology 2010;151:5741-50.
19. Chan SS, Twigg SM, Firth SM, Baxter RC. Insulin-like growth factor binding protein-3 leads to insulin resistance in adipocytes. J Clin Endocrinol Metab 2005;90:6588-95.

20. Kim HS, Ali O, Shim M, Lee KW, Vuguin P, Muzumdar R, et al. Insulin-like growth factor binding protein-3 induces insulin resistance in adipocytes in vitro and in rats in vivo. Pediatr Res 2007;61:159-64.

21. Mohanraj L, Kim HS, Li W, Cai Q, Kim KE, Shin HJ, et al. IGFBP-3 inhibits cytokine-induced insulin resistance and early manifestations of atherosclerosis. PLoS One 2013;8:e55084.

22. Palau N, Rebuffat SA, Altirriba J, Piquer S, Hanzu FA, Gomis R, et al. Role of IGFBP-3 in the regulation of $\beta$-cell mass during obesity: adipose tissue $/ \beta$-cell cross talk. Endocrinology 2012;153:177-87.

23. Chan SS, Schedlich LJ, Twigg SM, Baxter RC. Inhibition of adipocyte differentiation by insulin-like growth factorbinding protein-3. Am J Physiol Endocrinol Metab 2009;296:E654-63.

24. de Silva HC, Firth SM, Twigg SM, Baxter RC. Interaction between IGF binding protein-3 and TGF $\beta$ in the regulation of adipocyte differentiation. Endocrinology 2012;153:4799807

25. Penkov DN, Egorov AD, Mozgovaya MN, Tkachuk VA. Insulin resistance and adipogenesis: role of transcription and secreted factors. Biochemistry (Mosc) 2013;78:8-18.

26. Grohmann M, Sabin M, Holly J, Shield J, Crowne E, Stewart C. Characterization of differentiated subcutaneous and visceral adipose tissue from children: the influences of TNF-alpha and IGF-I. J Lipid Res 2005;46:93-103.

27. Baxter RC, Twigg SM. Actions of IGF binding proteins and related proteins in adipose tissue. Trends Endocrinol Metab 2009;20:499-505.

28. Yamanaka Y, Wilson EM, Rosenfeld RG, Oh Y. Inhibition of insulin receptor activation by insulin-like growth factor binding proteins. J Biol Chem 1997;272:30729-34.

29. Bang P, Brismar K, Rosenfeld RG. Increased proteolysis of insulin-like growth factor-binding protein-3 (IGFBP-3) in noninsulin-dependent diabetes mellitus serum, with elevation of a 29-kilodalton (kDa) glycosylated IGFBP-3 fragment contained in the approximately 130 - to $150-\mathrm{kDa}$ ternary complex. J Clin Endocrinol Metab 1994;78:111927.

30. Lee SW, Rhie YJ, Hwang IT, Han DK, Kim DH, Kim HS. The effect of obesity on serum growth factors, and insulinlike growth factor binding protein-3 proteolysis in children with simple obesity. J Korean Soc Pediatr Endocrinol 2005;10:195-203. 